American Journal of Histology and Cytology
(ISSN:2637-5117)

\title{
Expression of transcription factors (STAT 2, 3, 4, and 6, HDAC1, HDAC2) in craniopharyngioma
}

\section{Martha Lilia Tena-Suck. M.D. ${ }^{*}$, Wilhem Moreno. M.D. ${ }^{2}$, Sergio Zavala-Vega. PhD $^{3}$, Carmen Rubio. PhD $^{4^{*}}$}

${ }^{1}$ Departamento de Neuropatología. Instituto Nacional de Neurología y Neurocirugía, Manuel Velasco Suárez. Ciudad de México. ${ }^{2}$ Laboratorio de Neurofisiología. Instituto Nacional de Neurología y Neurocirugía, Manuel Velasco Suárez. Ciudad de México. México. ${ }^{3}$ Department of Neuropathology. National Institute of Neurology and Neurosurgery. México City, México. ${ }^{4}$ Laboratorio de Neurofisiología. Instituto Nacional de Neurología y Neurocirugía, Manuel Velasco Suárez. Ciudad de México.

\section{ABSTRACT}

Background: Craniopharyngioma is a benign tumor of the sellar region that is typically characterized by a maldevelopment tumor with a high recurrence rate, as well as substantial morbidity and mortality in the long term. Signal transducers and transcription activators have been identified as critical components of cytokine signaling pathways that have previously been documented in craniopharyngioma-related literature. Purpose: The primary goal of this investigation is to examine transcription factor expression in craniopharyngiomas. In addition, a clinical-pathological and immunohistochemistry correlation will be sought. The current study enlisted the participation of forty patients. AdaCPs exhibited: $\beta$-catenin STAT2, STAT3, STAT6, and HDAC1 expression. While, STAT4, HDAC2, and GATA 3 were all negative. TTF1 was found in proteinaceous substances within the cyst formation (OMF). $\beta-F G R$, DPGR, TNFa, and Nrf2 were found to be associated with inflammation, OMF presence, and finger protrusion in brain surrounding tissue or brain invasion. Conclusions: Tumor recurrence was associated with increased expression of STAT3, STAT6, HDAC, $\beta$-catenin, and TNFa in WLA when compared to no recurrence. Coexpression of $\beta$-catenin, STAT2, STAT3, and STAT6 with TNFa was also shown using double fluorescence merge stains. There was no association between HDAC1 and HDAC2 coexpression and $\beta$-catenin, notably in the WLAs. Discussion: Histologically complicated features include cystic and solid components, the latter of which is made up of diverse morphological cell types. HDAC1 and HDAC2 regulate the enhanced expression of inflammatory genes during inflammation and macrophage response.

Keywords: craniopharyngioma; transcriptions factors, proliferation,

*Correspondence to Author:

Martha Lilia Tena Suck Dr. and Carmen Rubio. PhD.

Department of Neuropathology. National Institute of Neurology and Neurosurgery. Manuel Velasco Suárez. Av. Insurgentes sur, 2877, La Joya, Tlalpan. ZIP Code: 14269. México City, México. Telephone 535556063822 ext. 2011.

ORCID0000-0002-4535-9231

How to cite this article:

Martha Lilia Tena-Suck, Wilhem Moreno, Sergio Zavala- Vega, Carmen Rubio. Expression of transcription factors (STAT 2, 3, 4, and 6, HDAC1, HDAC2) in craniopharyngioma.American Journal of Histology and Cytology, 2021, 4:12.

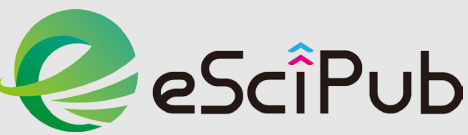

eSciPub LLC, Houston, TX USA. Website: https://escipub.com/ invasion, prognosis; STATs; HDAC1 and HDAC2, TNFa, $\beta$-catenin. 


\section{Introduction}

Craniopharyngiomas (CPs) account for $1-3 \%$ of all brain cancers ${ }^{[1]}$. There are two forms of histopathology. According to the WHO categorization [1], both forms are classification I. AdaCP is frequently related to a WNT pathway mutation, notably CTNNB1 ${ }^{[2]}$. These mutations and abnormal nuclear expressions of $\beta$-catenin accumulate in cell clusters ${ }^{[3]}$ whereas BRAF V600E mutations are found in Papillary craniopharyngioma $(\mathrm{PaCP})^{[3,4] \text {. }}$

The pituitary gland development is regulated by several signaling pathways and transcription factors (TFs) ${ }^{[4]}$. TFs that regulate gene expression are critical cellular workings that control advanced regulatory fundamentals training ${ }^{[5]}$, as well as their grouping of activities from multiple sauces, deliberate specificity, and strength in normal cellular events such as differentiation, proliferation, cell survival, apoptosis ${ }^{[4]}$, growth regulation and tumor invasion ${ }^{[5,6]}$, oncogenesis ${ }^{[5]}$, and angiogenesis ${ }^{[4]}$, among others.

Tyrosine phosphorylation is activated by TFs proteins, which is commonly done by cytokine receptor-associated kinases (JAKs) ${ }^{[5]}$. STAT proteins (STAT 1, 2, 3, 4, 5, and 6) are expressed in numerous cancers, including brain tumors ${ }^{[6]}$. To the best of our knowledge, few TFs have been studied in CPs.

The goal of this study is to look at the immunohistochemistry of several transcription factors (e.g., $\beta$-catenin, STAT2, STAT3, STAT4, STAT6, TTF1, GATA3, HDAC1, HDAC2, PDGR, EGFR, $\beta-F G F$, and TNF- $\alpha$ ) in craniopharyngioma, a clinical behavior associated with histological features, and recurring tumors.

\section{Materials and methods}

This study was authorized by our institutions' Ethics Committee following the Helsinki Declaration (P21-88). All patients gave consent for the use of the tissue removed, at the moment they approved the surgery. Forty formalin-fixed, paraffin-embedded tissue blocks from AdaCP biopsies were obtained retrospectively from the Department of Neuropathology archives at the
National Institute of Neurology and Neurosurgery in Mexico City between 2014 and 2017. The cases were separated between recurrence and non-recurrence cancers, as well as those with brain invasion and those without.

Each tumor sample's clinical statistics and detailed information are presented. Histopathological features investigated included dystrophic calcifications (DC), wet keratin (WK), whorl like arrays (WLA), the external epithelium (EE), in the palisading cell layer, cords, trabeculae, and lobules of well-differentiated epithelium, and stellate reticulum (SR), vascular proliferation (VP), brain invasion (BI), the nest of epithelial cells (NEC). Only AdaCPs were immunohistochemically examined in this investigation.

The same antibodies, concentrations, and retrieval procedures as previously described [5] were used for immunohistochemistry and immunofluorescence. Throughout this work, we looked at protein expression in several histological characteristics (DC, WK, WLA, EE, SR, in the palisading cell layer, cords, trabeculae, and lobules of well-differentiated epithelium, VP, the nest of epithelial cells, finger-like tumor, and brain adjacent tissue).

The histopathological features were analyzed for each case and for each primary antibody used: $\beta$-catenin (N1N2-2 genetex, dilution 1:100), signal transducers and activators of transcription proteins; STAT2 (sc 1686A-A7), STAT3(F2sc8019, dilution 1:100), and STAT4(sc398228, dilution 1:100) and STAT6 (sc-374021 AF488. Dilution 1:100). Histone deacetylase 1 (HDAC1, 1DE2, sc815998 dilution 1:100), Histone deacetylase 2 (HDAC2, antibody (10E2): sc-81598, dilution 1:100), Platelet-derived growth factor receptor (PDGR, GTX10848, dilution 1:100), beta fibroblastic growth factor (BFGF) (GTX65081-pro), GeneTex, dilution 1:100) and tumor necrosis factor (TNFa), Anti-TNF alpha antibody (GTX110520) | GeneTex, dilution 1:100). Epithelial growth factor (EGF) GTX29697, Gene Tex, dilution 1:100). Transcription termination factor, RNA polymerase I (TTF1, GTX129671, 
dilution 1:100). And Nuclear factor erythroid 2related factor 2 (NFE2L2, also known as Nrf2, A10): sc-365949, dilution 1:100) and GFRA2 (LSBio C-149958, dilution 1:100), GATA3 (GTX31401, dilution 1:100).

We estimated the positive fraction of stained tumor cells against TNF $\alpha$, PDGR, $\beta F G F$, TNFa, and $\mathrm{Nrf2}(0=0 \%, 1<10 \%, 2=10-50 \%, 3=50$ $80 \%, 4>80 \%$ ), and an intensity score (IS). The IS defines the estimated staining intensity $(0=$ no staining at all, $1=$ weak staining; 2 = moderate staining; 3 = strong staining).

\section{Immunofluorescence}

A double stain against TNFa, PDGR, $\beta F G F$, TNFa, and Nrf2 was performed. Tissue preparation and staining were performed as described above. Later, mouse monoclonal antibodies to STAT-3, 4 , and 6 and HDAC-1 y HDAC-2 were applied at a dilution of 1:400 and incubated 45 minutes at room temperature, followed by a 30 minute incubation with Poly-AP anti-mouse IgG (PV6110, Leica Biosystems, UK) at room temperature and visualized using ImmPACT Vector Red Alkaline Phosphatase (SK-5105, Vector Laboratory, CA) for 15 minutes. The percentage of different histopathological features was estimated by counting in forty contiguous cells using a $40 \times$ objective, with counts compared for consistency in 2-3 regions of each section when not limited by small tissue samples.

\section{Confocal microscopy}

For the confocal microscope study, STATs and HDAC1 and 2 (green) were correlated with $\beta$ - catenin and TNFa. Both were stained in red. DAPI in blue. A Nikon confocal microscope, eclipse Ti2, was used.

\section{Statistical analysis}

Data were analyzed using SPSS version 21.0.0 for Windows (SPSS Inc., Chicago, IL). Scale variables were presented as the mean \pm standard deviation (mean $\pm \mathrm{SD}$ ) or percentages as appropriate. Fisher's exact test was used to test the difference of immunohistochemical expression of each marker between AdaCP and PaCP and recurrence and non-recurrence tumors. The $P$ values positive were reported, the significance level was 0.05 .

\section{Results}

There were 40 adult cases of CPs in the research group. Thirty-six AdaCPs and four PaCPs were present. Table 1 displays clinical data from the patient's studies. Our sample size was made up of 19 females (48\%) and 21 males (53\%). The average age ranged from 17 to 55 years $(31.43 \pm 10.057)$. Females had a median age range of 29 years old, while males had a median age range of 31 years old. AdaCPs have a median age of 29 years old, while PaCPs have a typical age of 37 years old.

Symptom's time onset ranged from 1 to 9 months. The median follow-up length was 7 months, but for PaCPs it was 6 to 9 months. They were separated into two groups: recurring cancers $(n=20)$, non-recurrent tumors $(n=20)$, tumors with brain invasion $(n=27)$, and tumors without brain invasion $(n=13)$.

Table 1. Showed the clinical and demographic characteristics of the patients

\begin{tabular}{|l|l|l|l|l|l|l|}
\hline Clinical data & $\begin{array}{l}\text { Recurrent } \\
\text { Tumor } \\
\mathrm{n}=20(\%)\end{array}$ & $\begin{array}{l}\text { Nonrecurrent } \\
\mathrm{N}=20\end{array}$ & P-value & $\begin{array}{l}\text { Invasive } \\
\mathrm{n}=27\end{array}$ & Noninvasive & $\begin{array}{l}\text { P-value } \\
\mathrm{n}=13\end{array}$ \\
\hline Age & $27.50 \mathrm{yr}$ & $32.50 \mathrm{yr}$ & 0.90 & $26.00 \mathrm{yr}$ & $31.00 \mathrm{yr}$ & 0.181 \\
\hline $\begin{array}{l}\text { Female } \\
\text { Male }\end{array}$ & $\begin{array}{l}14(70) \\
6(30)\end{array}$ & $\begin{array}{l}5(25) \\
15(75)\end{array}$ & 0.004 & $\begin{array}{l}10(37) \\
17(63)\end{array}$ & $\begin{array}{l}9(69) \\
4(31)\end{array}$ & 0.056 \\
\hline Weight & $76.50 \mathrm{gr}$. & $73.50 \mathrm{gr}$. & 0.359 & $76 \mathrm{gr}$. & $76 \mathrm{gr}$. & 0.802 \\
\hline
\end{tabular}


Martha Lilia Tena-Suck et al., AJOHC, 2021, 4:12

\begin{tabular}{|l|l|l|l|l|l|l|}
\hline $\begin{array}{l}\text { AdaCps } \\
\text { PaCps }\end{array}$ & $\begin{array}{l}19(95) \\
1(5)\end{array}$ & $\begin{array}{l}17(85) \\
3(15)\end{array}$ & 0.292 & $\begin{array}{l}27(100) \\
0\end{array}$ & $\begin{array}{l}9(69) \\
4(31)\end{array}$ & 0.392 \\
\hline start time & $6(30)$ mo. & $9(45)$ mo. & 0.305 & $8(30)$ mo. & $9(69)$ mo. & 0.337 \\
\hline Follow-up & $1 \mathrm{mo}$ & $5 \mathrm{mo}$ & 0.009 & $8 \mathrm{mo}$ & $9 \mathrm{mo}$ & 0.337 \\
\hline $\begin{array}{l}\text { Solid } \\
\text { Cyst } \\
\text { Mixed }\end{array}$ & $\begin{array}{l}9(45) \\
8(40) \\
3(15)\end{array}$ & $\begin{array}{l}5(25) \\
12(60) \\
3(15)\end{array}$ & 0.379 & $\begin{array}{l}6(22) \\
16(59) \\
5(19)\end{array}$ & $\begin{array}{l}8(62) \\
4(31) \\
1(8)\end{array}$ & 0.050 \\
\hline Tumor size & $41 \mathrm{~mm}$. & $34 \mathrm{~mm}$. & 0.008 & $41 \mathrm{~mm}$. & $24 \mathrm{~mm}$. & 0.002 \\
\hline Improvement & $9(45)$ & $11(55)$ & 0.022 & $7(26)$ & $12(92)$ & 0.329 \\
\hline Follow-up & $2(10)$ & $12(60)$ & 0.009 & $6(22)$ & $12(92)$ & 0.584 \\
\hline Death & $12(60)$ & $3(15)$ & 0.000 & $23(85)$ & $12(92)$ & 0.285 \\
\hline
\end{tabular}

Table 2 depicts the various histological features results of CPs in relation to the different primary antibodies utilized. Figure 1 shows a histogram that illustrates the different histological features of recurrent and non-recurrent tumors.

\begin{tabular}{|c|c|c|c|c|c|c|}
\hline $\begin{array}{l}\text { Histopathological } \\
\text { Features }\end{array}$ & $\begin{array}{l}\text { Recurrent } \\
n=20\end{array}$ & $\begin{array}{l}\text { Nonrecurrent } \\
n=20\end{array}$ & $\begin{array}{l}\mathrm{P} \text { - } \\
\text { value }\end{array}$ & $\begin{array}{l}\text { Invasive } \\
\text { n-27 }\end{array}$ & $\begin{array}{l}\mathrm{N} \text {-invasion } \\
\mathrm{n}=13\end{array}$ & $\begin{array}{l}\mathrm{P}- \\
\text { value }\end{array}$ \\
\hline $\begin{array}{l}\text { Atypia EE } \\
\text { Negative } \\
\text { Weak } \\
\text { Moderate }\end{array}$ & $\begin{array}{l}4(20) \\
4(20) \\
8(40)\end{array}$ & $\begin{array}{l}10(50) \\
6(30) \\
4(20)\end{array}$ & 0.075 & $\begin{array}{l}4(15) \\
10(37) \\
11(41)\end{array}$ & $\begin{array}{l}3(23) \\
5(38) \\
5(38)\end{array}$ & 0.196 \\
\hline $\begin{array}{l}\text { Stellate reticulum } \\
\text { Solid pattern } \\
\text { Weak } \\
\text { moderated } \\
\text { strong }\end{array}$ & $\begin{array}{l}10(50) \\
5(25) \\
5(25)\end{array}$ & $\begin{array}{l}15(75) \\
4(20) \\
1(5)\end{array}$ & 0.002 & $\begin{array}{l}6(22) \\
14(52) \\
7(26)\end{array}$ & $\begin{array}{l}5(38) \\
6(46) \\
2(15)\end{array}$ & 0.514 \\
\hline WLAs & $15(75)$ & $5(25)$ & 0.002 & $13(48)$ & $7(54)$ & 0.053 \\
\hline $\begin{array}{l}\text { WK negative } \\
\text { WK weak } \\
\text { WK moderate }\end{array}$ & $\begin{array}{l}2(10) \\
8(40) \\
10(50)\end{array}$ & $\begin{array}{l}2(10) \\
7(35) \\
11\end{array}$ & 0.292 & \begin{tabular}{|l}
$1(4)$ \\
$6(22)$ \\
$20(74)$
\end{tabular} & $\begin{array}{l}1(8) \\
9(69) \\
3(23)\end{array}$ & 0.042 \\
\hline $\begin{array}{l}\text { DC negative } \\
\text { CD weak } \\
\text { CD moderate }\end{array}$ & $\begin{array}{l}0 \\
7(35) \\
10(50)\end{array}$ & $\begin{array}{l}0 \\
10(50) \\
11(55)\end{array}$ & 0.512 & \begin{tabular}{|l}
0 \\
$7(26)$ \\
$20(74)$
\end{tabular} & $\begin{array}{l}1(8) \\
8(62) \\
4(31)\end{array}$ & 0.061 \\
\hline $\begin{array}{l}\text { Macrophages } \\
\text { Negative } \\
\text { Weak } \\
\text { Moderate }\end{array}$ & $\begin{array}{l}3(15) \\
6(30) \\
11(55)\end{array}$ & $\begin{array}{l}7(35) \\
13(65) \\
1(5)\end{array}$ & 0.000 & $\begin{array}{l}2(7) \\
14(52) \\
11(41)\end{array}$ & $\begin{array}{l}1(8) \\
9(69) \\
3(23)\end{array}$ & 0.689 \\
\hline Giant cells & $16(80)$ & $8(40)$ & 0.000 & $20(74)$ & $11(85)$ & 0.376 \\
\hline Hemosiderin & $16(80)$ & $6(30)$ & 0.000 & $20(74)$ & $11(85)$ & 0.376 \\
\hline $\begin{array}{l}\text { Inflammation } \\
\text { Negative } \\
\text { Weak } \\
\text { Moderate } \\
\text { Strong }\end{array}$ & $\begin{array}{l}1(5) \\
3(15) \\
6(30) \\
10(50)\end{array}$ & \begin{tabular}{|l}
0 \\
$11(55)$ \\
$8(40)$ \\
$1(5)$
\end{tabular} & 0.047 & \begin{tabular}{|l|}
0 \\
$11(41)$ \\
$13(48)$ \\
$4(15)$
\end{tabular} & $\begin{array}{l}0 \\
10(77) \\
13(100) \\
0\end{array}$ & 0.001 \\
\hline
\end{tabular}


Martha Lilia Tena-Suck et al., AJOHC, 2021, 4:12

\begin{tabular}{|c|c|c|c|c|c|c|}
\hline $\begin{array}{l}\text { Granuloma } \\
\text { Negative } \\
\text { Weak } \\
\text { Moderate }\end{array}$ & $\begin{array}{l}3(15) \\
12(60) \\
5(20)\end{array}$ & $\begin{array}{l}8(40) \\
8(40) \\
4(20)\end{array}$ & 0.441 & $\begin{array}{l}14(52) \\
9(33) \\
4(15)\end{array}$ & $\begin{array}{l}6(46) \\
4(31) \\
3(23)\end{array}$ & 0.812 \\
\hline Cleft cholesterol & $12(60)$ & $6(30)$ & 0.053 & $20(74)$ & $11(85)$ & 0.376 \\
\hline OMF & $13(65)$ & $7(35)$ & 0.441 & $20(74)$ & $11(85)$ & 0.376 \\
\hline Fibroblast & $16(80)$ & $6(30)$ & 0.000 & $20(74)$ & $11(85)$ & 0.376 \\
\hline Finger protrusions & $15(75)$ & $4(20)$ & 0.067 & $17(63)$ & $4(31)$ & 0.023 \\
\hline
\end{tabular}

There was a statistically significant difference in the presence of greater WLAs (0.002), macrophages $(p=0.002)$, giant cells $(p=0.000)$, hemosiderin $(p=0.000)$, peritumoral fibroblasts $(p=0.000)$, and $S R$ with solid appearance $(p=0.047)$ with recurrent tumors versus those with no recurrent.

Both recurrent and non-recurrent tumors had more cellular atypia in the external epithelium, moist keratin, inflammation, granuloma formation, cholesterol crystals, OMF presence, fibroblast proliferation, and finger protrusions production in the patients studied. They were, however, not statistically significant. Only the presence of inflammation was a statistically significant value in invasive tumors $(p=0.001)$. There were no statistically significant differences between tumors that were brain invasive and those that were not. However, WLAs, inflammation, macrophages, wet keratin, and dystrophic calcifications are more common in these invasive tumors.

\section{Immunohistochemistry results}

\section{RECURRENT TUMORS}
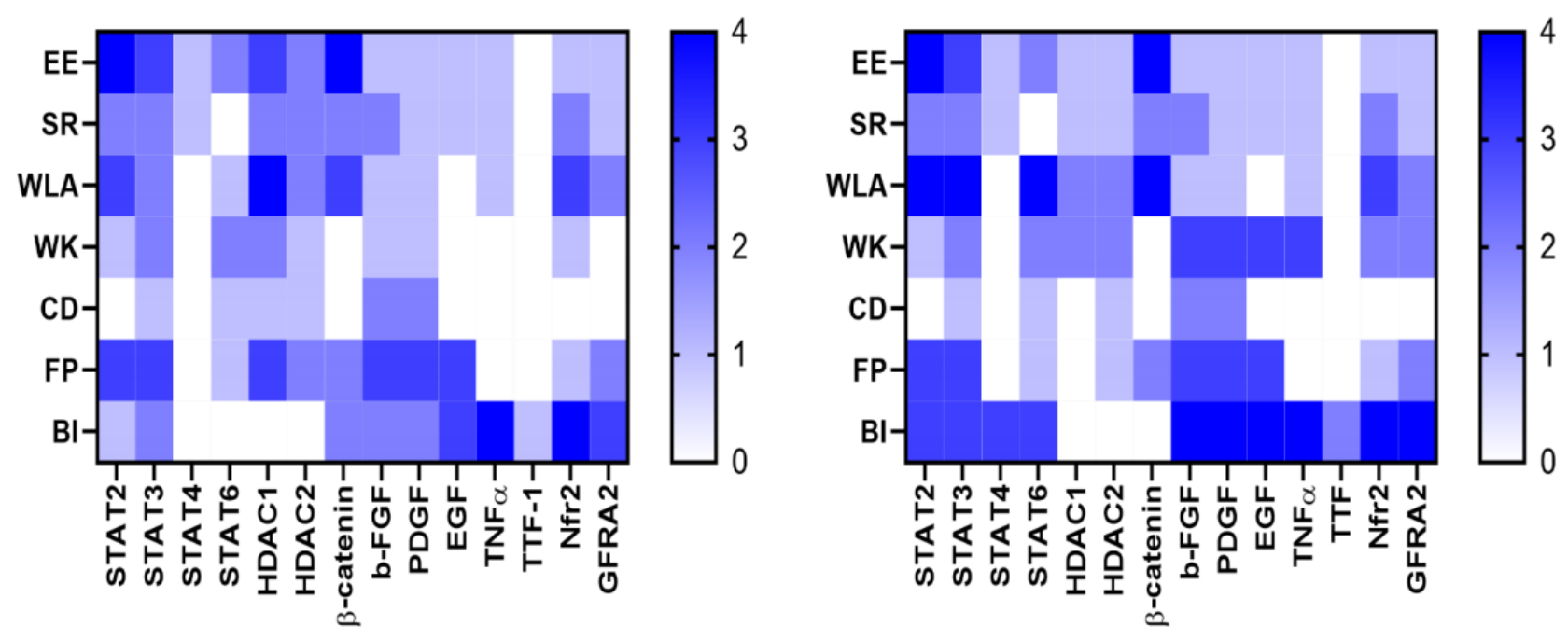

Figure 1. Heatmap showing the different primary antibodies used between the different histological features of AdaCPs in (a) recurrent tumors and (b) in the non-recurrent tumor. (c) Heatmap of the associations between TFs and $\beta$-catenin and in (d) the association between TFs +TNFa is observed.

Figure 1 depicts immunohistochemistry results based on the different primary antibodies employed. In the heat map, we observed that STAT 4 was higher in EE, FP, and $\mathrm{BI}$ in the recurrent compared to non-recurrent ones. STAT 6 was higher in the recurrent non-recurrent pathways in WLA and BI. HDAC1 and HCAC2 were both negative in recurring cases 
and mild in non-recurring cases. $\beta$-catenin was expressed higher in WLAs and FPs in recurrent tumors. BFGF, DPGF, EGF expressed higher immunoreaction in $\mathrm{BI}, \mathrm{EE}$, and FP. Its expression was higher in WLA and FP in recurrent tumors, while Nfr2 and GFRA2 were the same in $\mathrm{BI}$ and FP tissue in both tumors, and Nfr2 was higher in WLA in recurrent ones. TNFa was higher immunoreaction in $\mathrm{BI}, \mathrm{FP}, \mathrm{WK}$, and WLA in recurrent than in non-recurrent.

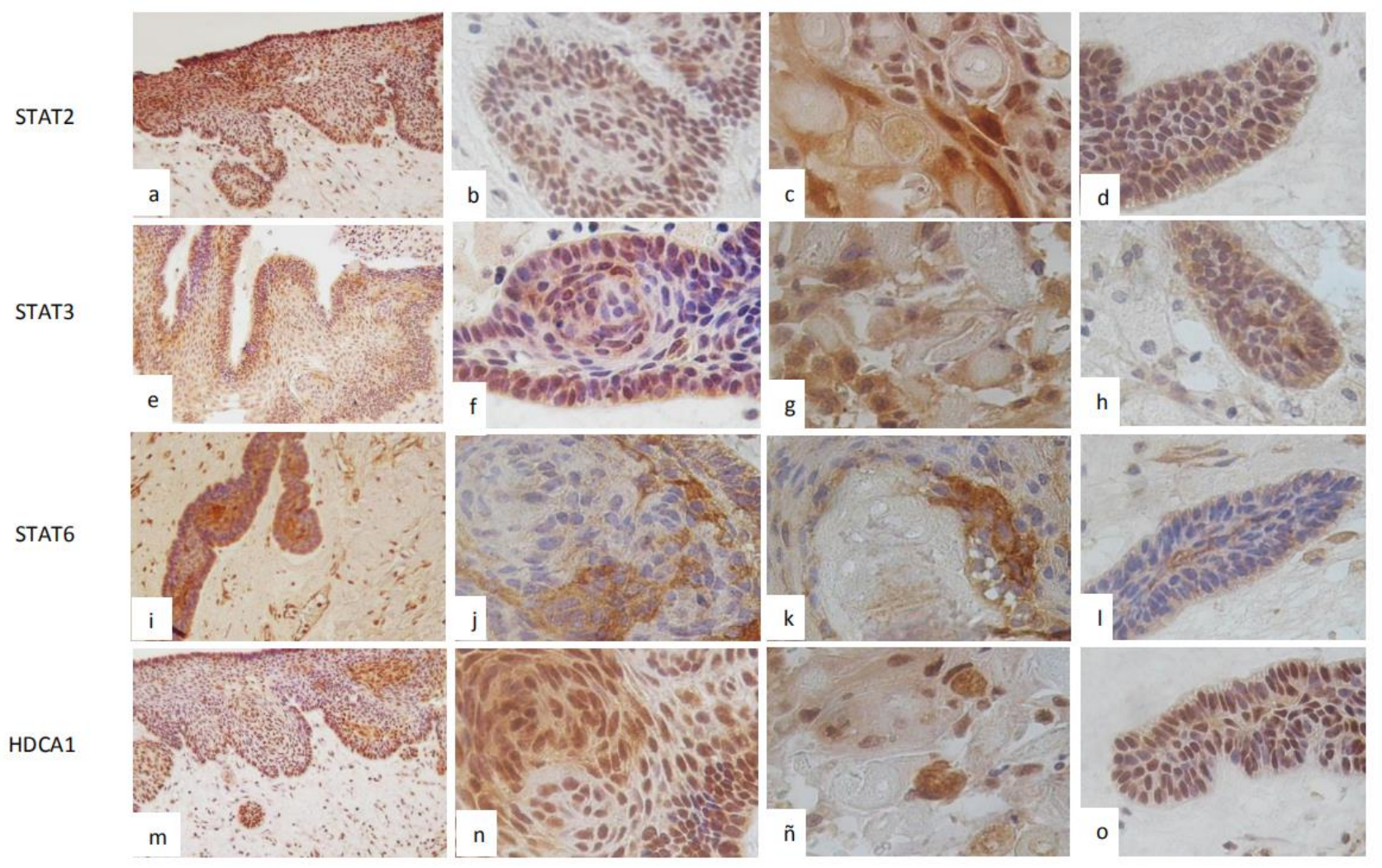

Figure 2: Characteristics of immunohistochemistry. (a) STAT2 was found to be positive in EE, SR, and (b) nuclear immunoreaction in WLA. (c) nuclear and cytoplasmic positive immunoreaction in the periphery of WK and DC basal cells, and (d) nuclear positive immunoreaction in the finger protrusions' peripheral epithelium. (e) STAT3 was shown to be positive in EE, SR, (f) strong cytoplasmic immunoreaction in WLA. (g) Nuclear and cytoplasmic positive immunoreaction in the basal cell of the periphery of WK and DC. (h) cytoplasmic positive immunoreaction in the peripheral epithelium of finger protrusions. (i) STAT6 was positive in EE and SR, (j) strong cytoplasmic and some cells with nuclear immunoreaction in WLA, (k) cytoplasmic positive immunoreaction in WK and DC periphery and endothelial cells, and (I) cytoplasmic positive immunoreaction in the peripheral epithelium and endothelial cells in finger protrusion. (m) HDAC1 was nuclear positive in cells in EE and SR, (n) strong cytoplasmic and some cells with nuclear immunoreaction in WLA, (n) nuclear and cytoplasmic positive immunoreaction in the basal cell of the periphery of WK and DC, and (o) finger protrusions cytoplasmic strong nuclear positive immunoreaction in the peripheral epithelium (Fig. 10). (IHQ stain $\times 400$, original magnifications).

STAT2 was positive in EE, SR (Fig.2a), nuclear immunoreaction in WLA was found (Fig. 2b). As well as nuclear and cytoplasmic positive immunoreaction in the basal cell of the WK and DC peripherical of (Fig. 2c). Finger protrusions were nuclear positive as immunoreaction in the peripheral epithelium (Fig. 2d).

STAT 3 was positive in EE, SR (Fig. 2e), strong cytoplasmic immunoreaction in WLA (Fig. 2f), nuclear and cytoplasmic positive immunoreaction in the peripherical basal cell of WK and DC (Fig. 2g). Finger protrusions were cytoplasmic positive immunoreaction in the peripheral epithelium (Fig. 2h).

STAT6 was positive in EE, SR (Fig 2i), strong cytoplasmic, and some cells with nuclear immunoreaction in WLA (Fig. 2j). The cytoplasmic positive immunoreaction was found in the 
peripherical basal cell of WK and DC and in endothelial cells (Fig. 2k). While the finger production was cytoplasmic positive immunoreaction in the peripheral epithelium and endothelial cells (Fig. 2l).

HDAC1 was nuclear positive in cells within EE and SR (Fig. 2m), in strong cytoplasm, and some cells with nuclear immunoreaction in WLA (Fig. 2n), nuclear and cytoplasmic positive immunoreaction in the basal cell of the peripherical of WK and DC (Fig. 2ñ). Finger production was cytoplasmic in strong nuclear positive immunoreaction in the peripheral epithelium (Fig. 20).

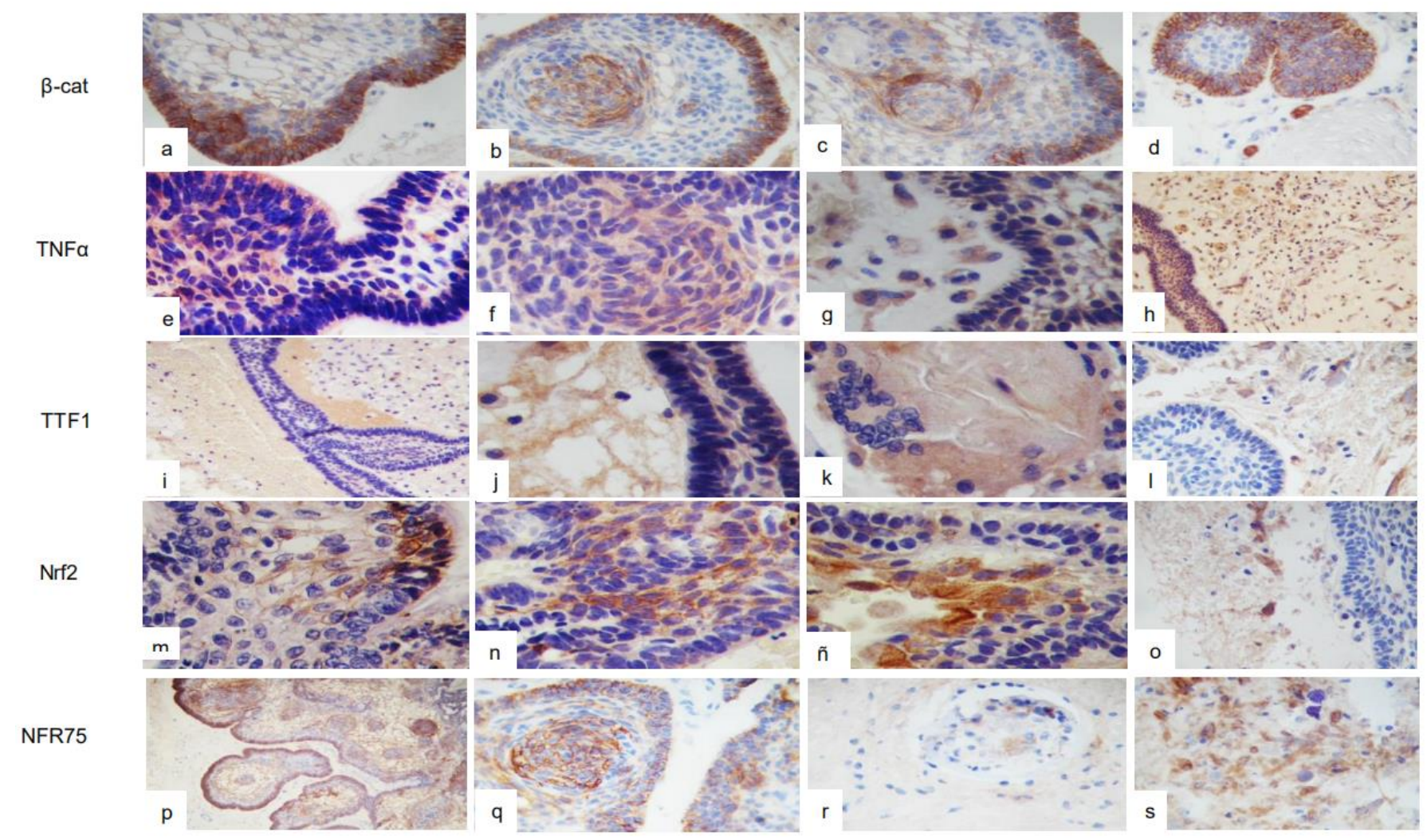

Figure 3. Immunohistochemistry features. (a) $\beta$-catenin was cytoplasmic positive in cells within EE and SR, (b) strong cytoplasmic, and some cells with nuclear immunoreaction in WLA. (c) Nuclear and cytoplasmic positive immunoreaction in peripherical basal cells of WK and DC, and in (d) cytoplasmic positive immunoreaction is showed in finger protrusions peripheral epithelium (IHQ $\times 400$ original magnifications). (e) TNFa, moderate cytoplasmic positive immunoreaction in EE and SR, (f) weak cytoplasmic immunoreaction in WLA. (g) Weak positive cytoplasmic immunoreaction in the basal cell of the peripherical of WK and DC and in macrophages, and in (h) cytoplasmic positive immunoreaction in the peripheral epithelium of the finger protrusions, in vessels and inflammatory cells (i) and (j), shows TTF1 positive reaction in OMF (proteinaceous material), and in giant multinucleated cells and WK in (k) and in FR in (l). (m) Anti-Nrf2 was moderate cytoplasmic positive in EE and SR, (n) weak cytoplasmic immunoreaction in WLA, (ñ) weak positive cytoplasmic immunoreaction in macrophages, and de finger protrusions, vessels, inflammatory cells in and RF was cytoplasmic positive immunoreaction (o). NFR75 positive reaction in EE (p), WLAs in membranal form(q) (IHQ stain x400), focally in the nest in brain adjacent tissue in (r), and RFs(s) (IHQx200).

$\beta$-catenin was cytoplasmic positive in cells within EE and SR (Fig. 3a), strong cytoplasmic, and some cells with nuclear immunoreaction in WLA (Fig. 3b), nuclear and cytoplasmic positive immunoreaction in the basal cell of the peripherical of WK and DC (Fig. 3c). Finger protrusions were cytoplasmic positive immune- reaction in the peripheral epithelium (Fig. 3d).
TNFa was moderate as cytoplasmic positive cells in EE and SR (Fig 3e), weak cytoplasmic immunoreaction in WLA (Fig. 3f), there was weak cytoplasmic positive immunoreaction in the peripherical basal cell of WK and DC and in macrophages (Fig. 3g). Finger protrusions were cytoplasmic positive immunoreaction in the peripheral epithelium and vessels and inflame- 
matory cells (Fig. 3h).

TTF1 was positive in OMF (Fig. $3 i$ and $3 j$ ), in giant multinucleated cells, in WK (Fig. 3k), and in FR (fig. 3I). Anti-Nrf2 and GFRA2 were moderate in cytoplasmic positive cells within EE and SR (Fig. 3m), weak cytoplasmic immunoreaction was found in WLA (Fig. 3n), as well as positive weak cytoplasmic positive immunoreaction in macrophages (Fig. 3ñ). Finger protrusions were cytoplasmic positive with immunoreaction inside vessels and inflammatory cells and RF (Fig. 3o). STAT1 and GATA3 were negative with immunoreaction in all the histological features in both AdaCPs types.

\section{Confocal microscopy results}

STAT2 and $\beta$-catenin were positive in the external epithelium and expressed (Fig. 4a-4d). As in the WLAs, there was coexpression (Fig. 4e-4h).
Likewise, STAT 4(Fig 4i-4I) and STAT 6 were expressed in the WLAs (Figs. $4 m-4 p$ ). STAT4 did not co-express with $\beta$-catenin. HDAC1 is positive in the external epithelium and was negative in the WLAs. They did not co-express with $\beta$-catenin, however (Fig. 4i-4I). STAT6 coexpressed with -catenin (Fig. 4m-4p). In the WLAs, HDAC1 did not coexpress with $\beta$-catenin (Fig. 5a-5d) or HDAC2 (Fig. 5e-5h). TNFa was shown to be coexpressed with STAT3 and STAT2 (Fig. $5 e-5 h)$.

Despite the lack of statistical significance, the association between the several primary antibodies utilized and the histology figures revealed an increase in the expression of STAT3, STAT6, HDAC1, HDAC2 + $\beta$-catenin and in association with TNFa in recurrent versus non-recurrent tumors.

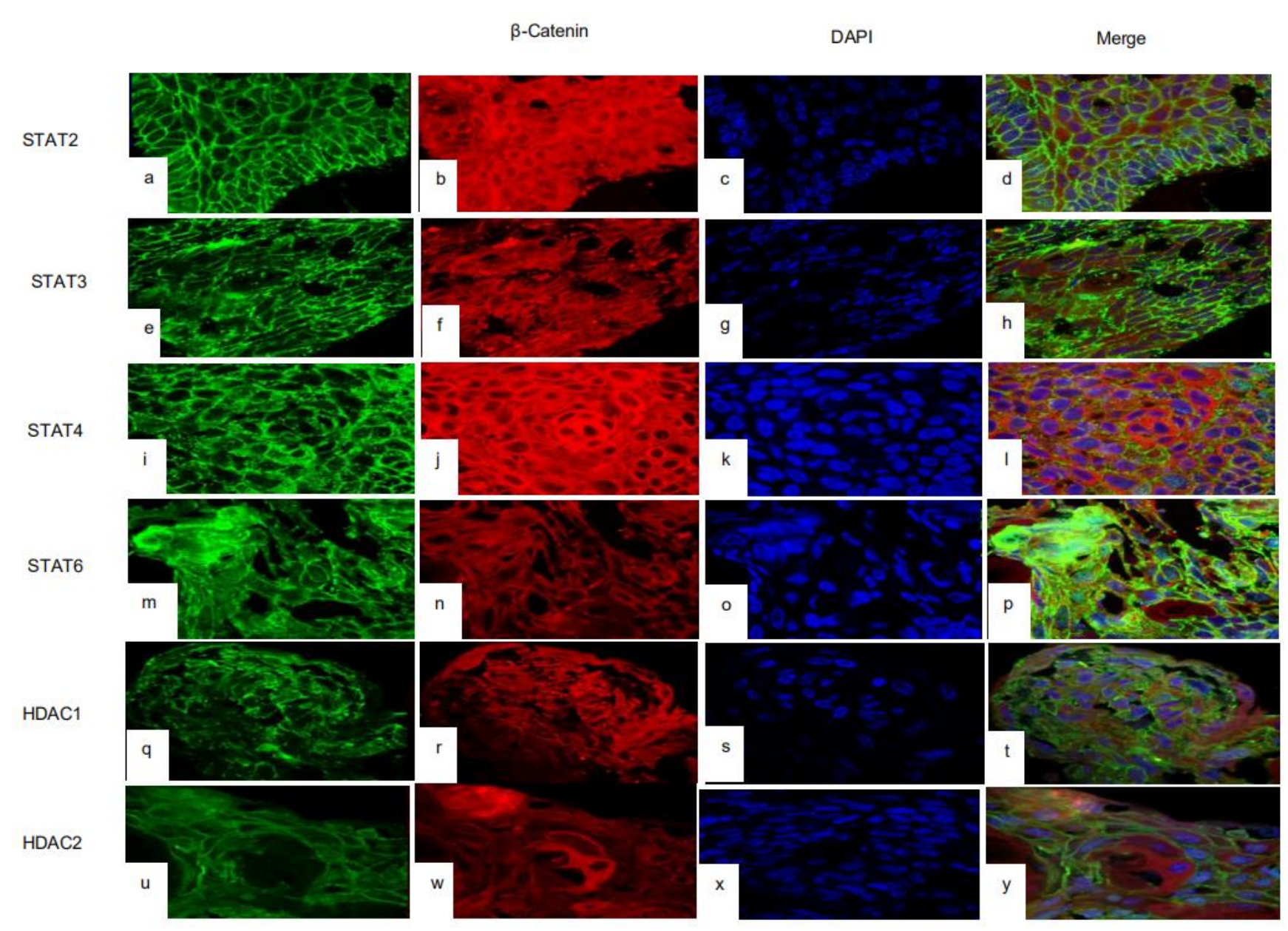

Figure 4. Confocal microscopy by double immunoflourece images illustrating the TFs deferments in association with $\beta$ catenin. As showed: (a) the immunoexpresion of STAT-2 (green), (b) $\beta$-catenin (red), (c) DAPI (blue) and (d) marge. STAT3 + $\beta$-catenin in (e), (f), (g) and (h). STAT4+ $\beta$-catenin in (i) (j), (k), and (l). STAT6+ $\beta$-catenin in (m), (n), (o), and (p). HDAC1+ $\beta$-catenin in (q), (r), (s) and (t). HDAC2 in $(u),(w),(x)$ and $(y)$. 


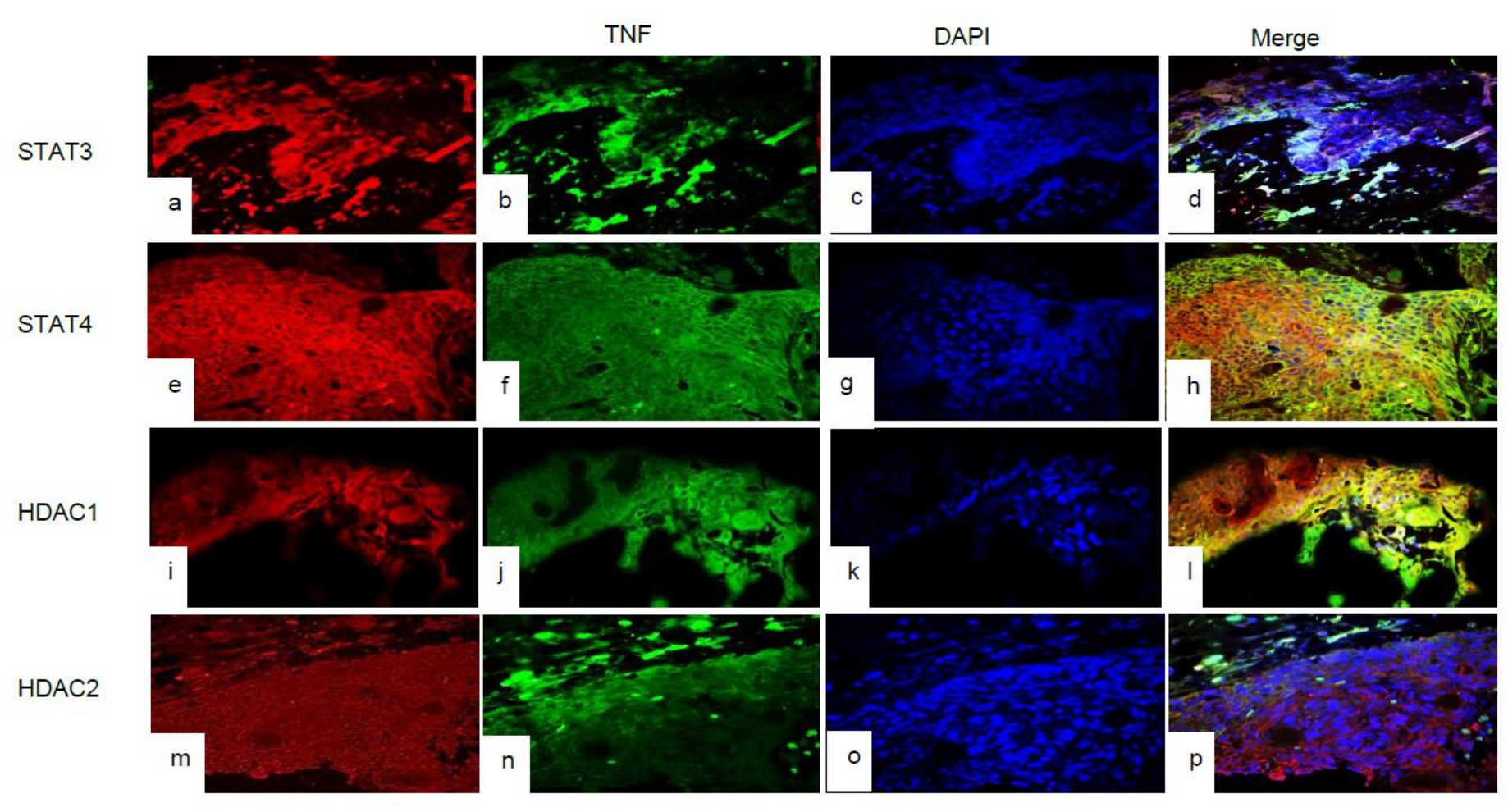

Figure 5. Confocal microscopy by double immunoflourece images showing the TFs deferments in association with TNFa. Observation of (a) STAT3 (red) positive immunoreaction, (b) TNFa in (green), DAPI in (blue) and in marge in (d). STAT4 + TNFa in (e), (f), (g), and (h). HDAC1+ TNFa in (i), (j), (k) and (l). and HDAC2+ TNFa positive reaction in (m), (n), (o) and (p).

\section{Discussion}

Transcription factors like Sox2, Sox9 OCT-4, KLF4, CD44, and CD133 (Prominin 1), SRY-related HMG Box [7], are well-known stem cell markers studied to be involved in pituitary development ${ }^{[7,8]}$. Several stemness markers have been previously studied in AdaCP cell clusters associated with nuclear $\beta$-catenin accumulation [7]. Still, it has been shown before that Sox9 overexpression is identified with $\mathrm{Wnt} / \beta$-catenin signaling activation in CPs ${ }^{[8]}$. These facts are fascinating concerning $\mathrm{CPs}$ as $\beta$-catenin accumulating cells with subsequent Wnt signaling activation are the marker of AdaCP [7].

We believe that each structure or histological feature that forms in the tumor context represents different changes associated with various transcription factors, and in association with either rupture of the external epithelium and exit of the OMF into the adjacent brain tissue ${ }^{[9]}$, senescence [10], oxidative stress factors, or an intense reaction of the tumor-specific cellular environment in the surrounding brain tissue ${ }^{[11,12]}$.
The positive immunoexpression of STAT3 and 6, HDAC1, TNFa, DPGF, $\beta F G F$ in these areas was observed in several vessels. As well as the participation of angiogenic factors, inflammatory processes, and tumor spread. Formation of finger-like tumors protrusions and brain adjacent invasion was also prevailing ${ }^{[1,7,8]}$. Additionally, WLA presence was related to the greater anomalous or nuclear $\beta$-catenin expression [9]. These data suggest that Wnt pathway activation contributes to the pathogenesis and prognosis of AdaCPs [10]. Stronger $\beta$-catenin immunostaining is associated positively with tumor progression. MYC [10] Wnt pathway genes have been overexpressed in AdaCPs harboring CTNNB1 mutations and in patients with progressive disease $[9,10]$. On the one hand, the $\beta$-catenin mutation has been known as the key inflammatory mediator NF-KB in response to upregulated $\mathrm{Wnt} / \beta$ catenin activation ${ }^{[9,12]}$. On the other hand, $\beta$ catenin-accumulating cluster cells and palisading epithelium have been observed, surrounded by a florid glial reaction and the immune microenvironment ${ }^{[7,9-14]}$. 
STATs are cytoplasmic latent proteins discovered in the context of cytokine signaling and growth factor signaling. These are frequently linked with AdaCPs and malignant transformation in themselves and other brain tumors ${ }^{[5,6]}$. In this analysis, we observed indeed that STAT2, STAT3, STAT6, and HDAC1 were strongly positive in tumors. But most importantly, these proteins are linked to the inflammatory response ${ }^{[16]}$.

STAT3 aids critical roles in some cellular processes, including cell cycle, cell proliferation, cellular apoptosis, and tumorigenesis ${ }^{[6]}$, the output of which is to modulate gene expression. In addition, it induces tumor angiogenesis by vascular endothelial growth factor induction upregulation modulating immune functions ${ }^{[15]}$, induces microglia and macrophage activation ${ }^{[16]}$, and inhibited tumor growth [15]. In various cancer types resulting in substantial adverse effects, such as drug resistance and poor prognosis.

STAT6 has been demonstrated to control numerous pathologic inflammatory responses. Cytokines IL-4 and IL-13. And also interacted with and immune cells ( $B$ and $T$ cells, macrophages, dendritic cells, and innate lymphoid cells in brain tumors ${ }^{[17]}$. STAT6 signaling inactivation can occur via ubiquitination and proteasomal degradation, facilitating cancer cell survival in a hypoxic microenvironment ${ }^{[18]}$. STAT6 increases HIF-1a expression via mTOR/S6K/S6 [17,19]. Expression of stat6 in Cps is correlated to tumor invasion and recurrent tumors.

Histone deacetylases (HDACs) have the role of being involved in its impacted pathways as stem cell maintenance, including Wnt, Notch, cell cycle, and transcriptional misregulation in cancer [20]. HDAC1 and HDAC3 have been examined as inversely correlated with survival, including cell cycle, apoptosis, DNA-damage response, and autophagy [20]. HDAC inhibitors (HDACi) effectively inhibit tumor growth and progression [20]. Gene silencing of HDAC1 and HDAC2 resulted in increased cytokine production, NF-KB nuclear translocation induced HDAC2 activity. Thus, macrophage expression was reduced, resulting in amplification of the inflammatory response [20,21]. Since HDAC1 and HDAC2 are not coexpressed with $\beta$-catenin in WLA. So, we consider that they are growth inhibitors and CPs invasion.

Those surrounded by a florid glial had a reaction with immune cells, $\beta F G F$, TGFB, and BMP families of secreted factors. Besides, signaling to adjacent cells was evidenced by immunostaining against the phosphorylated proteins pERK1/2, pSMAD3, and pSMAD1/5/9 [7]. We found a strong expression of BFGF, DPGF, TNFa in association with inflammation. HDAC2 gene regulator acts in the cell cycle, apoptosis, cell adhesion, suppresses inflammatory gene expression and migration, and appears to be secondary to increased oxidative and nitrative stress [21]. Together with HDAC1, HDAC2 regulates genes transcription as they are implicated in hematopoiesis, epithelial cell differentiation. In our analyzed cases, they were positive in the EE, SR, and WLA. However, they did not co-express with $\beta$-catenin expression. Histones deacetylation is associated with the transcriptional silencing pathway ${ }^{[12]}$, and in CPs they are growth and invasion inhibitors.

The AdaCP Intracystic OMF has been revealed to contain inflammatory modulators. Thymosins $\beta 4$ and $\beta 10$ have been identified in AdaCPs cystic fluid [11-13]. As well as apolipoproteins, albumin, IL1B, IL6, IL8, IL10, IL18, TNFa, and IFNG in the cystic OMF have been identified ${ }^{[7]}$. The cases allowed us to reveal enrichment for terms related to immune/defense response, inflammation, and sterol metabolism and in tumor behavior ${ }^{[9,10,12]}$. When OMF exiting produces overexpression of HDAC1 and TNFa and stimulation of epithelial cells. As well as an intense inflammatory response that could be inhibitory to tumor growth.

Extracellular matrix activation and overexpression of $\beta F G F$, DPGR, TNFa, Nrf2, and GFRA2 suggests that when OMF exits out of the tumor, it is mediated by an intense inflammatory response. As well as by STATs and HDAC1 modifying the tumor microenvironment ${ }^{[22] .}$ 
Nrf2, other transcription factor partners as well by forming a nuclear complex with the ubiquitinconjugating enzyme UbcM2. It is involved in inflammatory diseases ${ }^{[23]}$ and might be a useful biomarker to predict gliomas grade. It could potentially be associated with the migration and invasion - as well as with renewal - of glioma stem cells' cellular tumors behavior [23,24]. Nfr2 expression in CPs is directly related to the giant cells and in the basal cells of the WK formations and the formation of cholesterol crystals [23].

In summary, the STATs and other growth factors seem to play essential roles not only in CPs formation. But also in processes involving the tumors that develop surrounding the brain parenchyma. The inverse relation of expression and activation of the Wnt signaling pathway in AdaCP is particularly interesting. Because immunohistochemistry clearly demonstrates a possible impact of $\beta$-catenin cellular distribution pattern as being essential for subsequent Wnt target gene activation. In the inflammation processes activation, there is an activation of MC secondary to proliferation and tumor recurrence. In the future, these relations should be investigated on the molecular level in more detail. Histones deacetylation is associated with the transcriptional silencing pathway. And in craniopharyngiomas, they are growth and invasion inhibitors. HDACs could be a drug target in pediatric and adult PCs.

\section{Footnotes}

Declaration of interest: We declare that no conflict of interest could be perceived as prejudicing the impartiality of the research reported.

Author Contributions: Conceptualization: MLTS. Data curation: MLTS, MCR. Formal analysis: MCR, WM, MLTS, SZV. Funding acquisition: MLTS, MCR. Investigation: MLTS, MCR, WM, SZV

Methodology: MLTS, MCR, WM. Project administration: MLTS. Resources: MLTS. Software: MCR, WM. Supervision: MLTS.MCR. Validation: MLTS, MCR. Visualization: MLTS, MCR and WM
Writing - original draft: MLTS, MCR, WM. Writing - review \& editing: MLTS, WM, MCR

\section{Conflict of interest statement}

The authors declare that the research was conducted without any commercial or financial relationships that could be construed as a potential conflict of interest.

\section{Ethics}

Experiments were performed under Research Ethics Committee approval (P20/88). Where we don't require informed consent for each patient procedure.

\section{Consent to participate}

Consent was given by every participant when they signed the surgery consent.

\section{Funding}

We had no private or public funding for this study.

\section{Disclosure}

We have no conflict of interest to disclose.

\section{Acknowledgments}

The use of Cofocal microscope was thanks to the the "Consejo Nacional de Ciencia y Tecnología (CONACYT)", México, grant number 300461. Also, we acknowledge Brenda Peralta for her technical assistance.

\section{Abbreviations}

Craniopharyngioma (CP), World Health Organization (WHO), adamantinomatous craniopharyngioma (AdaCP). Papillary craniopharyngioma $(\mathrm{PaCP})$, pancitokeratins ( $\mathrm{CK})$, immunohistochemistry (IHQ). Transcription factors (TFs), cytokine receptor-associated kinases (JAKs). Signal transducers and activators of transcription proteins (STAT) GATA-binding factor, Anti-Histone Deacetylase 1 (HDAC1 and 2), beta fibroblast growth factor ( $\beta$-FGF) tumoral necrosis factor- alfa (TNF- $\alpha$ ), Platelet-derived growth factor receptor (PDGR), epithelial growth factor (EGF), dystrophic calcifications (DC), wet keratin (WK), the whorl-like arrays (WLA), the external epithelium $(E E)$, stellate reticulum (SR), vascular proliferation (VP), brain invasion $(\mathrm{BI})$, the nest of epithelial cells (NEC), finger-like 
tumor protrusions (FLTP), inflammatory areas (IA). Epithelial Perivascular layer (EPVL), extracellular matrix (ECM). Activated macrophages (AAMs). Associated Secretory Phenotype (SASP), Cancer Stem Cells (CSCs). Transcription termination factor, RNA polymerase I (TTF1), Nuclear factor erythroid 2-related factor 2 (NFE2L2, also known as Nrf2), Glial cell linederived neurotrophic factor receptor alpha 2 (GFRA2).

\section{References}

[1] D.N. Louis, H. Ohgaki, O.D. Wiestler, W.K. Cavenee, P.C. Burger, A. Jouvet, B.W. Scheithauer, P. Kleihues, WHO classification of tumours of the central nervous system, Forth edit, International Agency of Reserch on Cancer, Lyon, 2016.

[2] K. Kato, Y. Nakatani, H. Kanno, Y. Inayama, R. Ijiri, N. Nagahara, T. Miyake, M. Tanaka, Y. Ito, N. Aida, K. Tachibana, K.I. Sekido, Y. Tanaka, Possible linkage between specific histological structures and aberrant reactivation of the Wnt pathway in adamantinomatous craniopharyngioma, J. Pathol. 203 (2004). https://doi.org/10.1002/path.1562.

[3] J.P. Martinez-Barbera, R. Buslei, Adamantinomatous craniopharyngioma: pathology, molecular genetics and mouse models., J. Pediatr. Endocrinol. Metab. 28 (2015) 7-17. https://doi.org/10.1515/jpem2014-0442.

[4] P.K. Brastianos, G.M. Shankar, C.M. Gill, A. Taylor-Weiner, N. Nayyar, D.J. Panka, R.J. Sullivan, D.T. Frederick, M. Abedalthagafi, P.S. Jones, I.F. Dunn, B. V Nahed, J.M. Romero, D.N. Louis, G. Getz, D.P. Cahill, S. Santagata, W.T. Curry, F.G. Barker, Dramatic Response of BRAF V600E Mutant Papillary Craniopharyngioma to Targeted Therapy., J. Natl. Cancer Inst. 108 (2016). https://doi.org/10.1093/jnci/djv310.

[5] T. Bowman, R. Garcia, J. Turkson, R. Jove, STATs in oncogenesis., Oncogene. 19 (2000) 2474-88. https://doi.org/10.1038/sj.onc.1203527.

[6] J. Bromberg, J.E. Darnell, The role of STATs in transcriptional control and their impact on cellular function., Oncogene. 19 (2000) 246873. https://doi.org/10.1038/sj.onc.1203476.

[7] V. Thimsen, N. John, M. Buchfelder, J. Flitsch, R. Fahlbusch, H. Stefanits, E. Knosp, M. Losa, R. Buslei, A. Hölsken, Expression of SRY- related HMG Box Transcription Factors (Sox) 2 and 9 in Craniopharyngioma Subtypes and Surrounding Brain Tissue., Sci. Rep. 7 (2017) 15856. https://doi.org/10.1038/s41598-01715977-3.

[8] M. Garcia-Lavandeira, C. Saez, E. DiazRodriguez, S. Perez-Romero, A. Senra, C. Dieguez, M.A. Japon, C. V Alvarez, Craniopharyngiomas express embryonic stem cell markers (SOX2, OCT4, KLF4, and SOX9) as pituitary stem cells but do not coexpress RET/GFRA3 receptors., J. Clin. Endocrinol. $\begin{array}{llll}\text { Metab. } & 97 & \text { (2012) }\end{array}$ https://doi.org/10.1210/jc.2011-2187.

[9] M.L. Tena-Suck, A.Y. Morales-Del Ángel, M.E. Hernández-Campos, F. Fernández-Valverde, A. Ortíz-Plata, A.D. Hernández, A. Santamaría, Ultrastructural characterization of craniopharyngioma at the tumor boundary: A structural comparison with an experimental toxic model using "oil machinery" fluid, with emphasis on Rosenthal fibers., Acta Histochem. $117 \quad$ (2015) 696-704. https://doi.org/10.1016/j.acthis.2015.09.006.

[10] J.M. Gonzalez-Meljem, J.P. Martinez-Barbera, Senescence drives non-cell autonomous tumorigenesis in the pituitary gland., Mol. Cell. Oncol. $\quad 5 \quad$ (2018) e1435180. https://doi.org/10.1080/23723556.2018.143518 0.

[11]J.R. Apps, G. Carreno, J.M. Gonzalez-Meljem, S. Haston, R. Guiho, J.E. Cooper, S. Manshaei, N. Jani, A. Hölsken, B. Pettorini, R.J. Beynon, D.M. Simpson, H.C. Fraser, Y. Hong, S. Hallang, T.J. Stone, A. Virasami, A.M. Donson, D. Jones, K. Aquilina, H. Spoudeas, A.R. Joshi, R. Grundy, L.C.D. Storer, M. Korbonits, D.A. Hilton, K. Tossell, S. Thavaraj, M.A. Ungless, J. Gil, R. Buslei, T. Hankinson, D. Hargrave, C. Goding, C.L. Andoniadou, P. Brogan, T.S. Jacques, H.J. Williams, J.P. Martinez-Barbera, Tumour compartment transcriptomics demonstrates the activation of inflammatory and odontogenic programmes in human adamantinomatous craniopharyngioma and identifies the MAPK/ERK pathway as a novel therapeutic target., Acta Neuropathol. 135 (2018) 757-777. https://doi.org/10.1007/s00401-018-1830-2.

[12] A.M. Donson, J. Apps, A.M. Griesinger, V. Amani, D.A. Witt, R.C.E. Anderson, T.N. Niazi, G. Grant, M. Souweidane, J.M. Johnston, E.M. Jackson, B.K. Kleinschmidt-DeMasters, M.H. Handler, A.-C. Tan, L. Gore, A. Virasami, J.M. Gonzalez-Meljem, T.S. Jacques, J.P. Martinez- 
Barbera, N.K. Foreman, T.C. Hankinson, Molecular Analyses Reveal Inflammatory Mediators in the Solid Component and Cyst Fluid of Human Adamantinomatous Craniopharyngioma, J. Neuropathol. Exp. Neurol. $\quad 76 \quad$ (2017) 779-788. https://doi.org/10.1093/jnen/nlx061.

[13] R. Buslei, A. Hölsken, B. Hofmann, J. Kreutzer, F. Siebzehnrubl, V. Hans, F. Oppel, M. Buchfelder, R. Fahlbusch, I. Blümcke, Nuclear beta-catenin accumulation associates with epithelial morphogenesis in craniopharyngiomas., Acta Neuropathol. 113 (2007) 585-90. https://doi.org/10.1007/s00401006-0184-3.

[14] C.E.B. Jucá, L.M. Colli, C.S. Martins, M.L. Campanini, B. Paixão, R.V. Jucá, F.P. Saggioro, R.S. de Oliveira, A.C. Moreira, H.R. Machado, L. Neder, S.R. Antonini, M. de Castro, Impact of the Canonical Wnt Pathway Activation on the Pathogenesis and Prognosis of Adamantinomatous Craniopharyngiomas., Horm. Metab. Res. 50 (2018) 575-581. https://doi.org/10.1055/a-0593-5956.

[15] L. Zhang, D. Alizadeh, M. Van Handel, M. Kortylewski, H. Yu, B. Badie, Stat3 inhibition activates tumor macrophages and abrogates glioma growth in mice., Glia. 57 (2009) 145867. https://doi.org/10.1002/glia.20863.

[16] K. Hirahara, A. Onodera, A. V Villarino, M. Bonelli, G. Sciumè, A. Laurence, H.-W. Sun, S.R. Brooks, G. Vahedi, H.-Y. Shih, G. Gutierrez-Cruz, S. Iwata, R. Suzuki, Y. Mikami, Y. Okamoto, T. Nakayama, S.M. Holland, C.A. Hunter, Y. Kanno, J.J. O'Shea, Asymmetric Action of STAT Transcription Factors Drives Transcriptional Outputs and Cytokine Specificity., Immunity. 42 (2015) 877-89. https://doi.org/10.1016/j.immuni.2015.04.014.

[17] S.J. Park, H. Kim, S.H. Kim, E.-H. Joe, I. Jou, Epigenetic downregulation of STAT6 increases
HIF-1a expression via mTOR/S6K/S6, leading to enhanced hypoxic viability of glioma cells., Acta Neuropathol. Commun. 7 (2019) 149. https://doi.org/10.1186/s40478-019-0798-z.

[18] H. Yu, H. Lee, A. Herrmann, R. Buettner, R. Jove, Revisiting STAT3 signalling in cancer: new and unexpected biological functions., Nat. Rev. Cancer. 14 (2014) 736-46. https://doi.org/10.1038/nrc3818.

[19] S.F.H. Waqas, G. Ampem, T. Röszer, Analysis of IL-4/STAT6 Signaling in Macrophages., Methods Mol. Biol. 1966 (2019) 211-224. https://doi.org/10.1007/978-1-4939-9195-2_17.

[20] K.J. Falkenberg, R.W. Johnstone, Histone deacetylases and their inhibitors in cancer, neurological diseases and immune disorders., Nat. Rev. Drug Discov. 13 (2014) 673-91. https://doi.org/10.1038/nrd4360.

[21]J.E. Bolden, M.J. Peart, R.W. Johnstone, Anticancer activities of histone deacetylase inhibitors, Nat. Rev. Drug Discov. 5 (2006) 769784. https://doi.org/10.1038/nrd2133.

[22] S. Minucci, P.G. Pelicci, Histone deacetylase inhibitors and the promise of epigenetic (and more) treatments for cancer., Nat. Rev. Cancer. 6 (2006) 38-51. https://doi.org/10.1038/nrc1779.

[23] M. Kanamori, T. Higa, Y. Sonoda, S. Murakami, M. Dodo, H. Kitamura, K. Taguchi, T. Shibata, M. Watanabe, H. Suzuki, I. Shibahara, R. Saito, Y. Yamashita, T. Kumabe, M. Yamamoto, $\mathrm{H}$. Motohashi, T. Tominaga, Activation of the NRF2 pathway and its impact on the prognosis of anaplastic glioma patients., Neuro. Oncol. 17 (2015) 555-65. https://doi.org/10.1093/neuonc/nou282.

[24] J. Ecker, O. Witt, T. Milde, Targeting of histone deacetylases in brain tumors, CNS Oncol. 2 (2013) 359-376. https://doi.org/10.2217/cns.13.24.

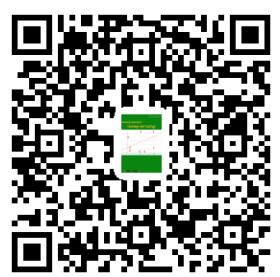

